V Seminário Anual Científico e Tecnológico | Bio-Manguinhos

\title{
BIO 02 - Modelagem, docking e dinâmica molecular de dois fragmentos de anticorpos contra o antígeno de superfície do vírus da Hepatite B
}

Artur Hermano Sampaio Dias ${ }^{1 *}$; Aline de Oliveira Albuquerque ${ }^{1}$; Alexandre Bezerra Conde Figueiredo²; João Hermínio Martins da Silva1; Márcia Arissawa².

1 Fiocruz / Ceará;

2 Bio-Manguinhos / Fiocruz, Laboratório de Tecnologia de Anticorpos Monoclonais.

\section{Introdução:}

A hepatite B, um dos grandes problemas de saúde pública atuais, pode levar pacientes crônicos a um transplante de fígado seguido de tratamento com imunossupressores administrados conjuntamente a anticorpos monoclonais. Fragmentos variáveis de cadeia única $(s c F v)$ são produtos de anticorpos adequados para esse tipo de tratamento. Desta forma, este trabalho apresenta o início do processo de humanização de dois clones de anticorpos monoclonais murinos, 19DD1AE3 e 19CC6CG2, obtidos pelo Laboratório de Tecnologia de Anticorpos Monoclonais da Fundação Oswaldo Cruz.

\section{Objetivo:}

O objetivo desse estudo foi obter as estruturas tridimensionais para cada clone, elucidar seu modo de ligação através de docking contra o antígeno de superfície do vírus da hepatite B e simular in silico seu comportamento dinâmico contra esse antígeno em um meio aquoso.

\section{Metodologia:}

A obtenção dos modelos tridimensionais dos dois clones foi feita por meio de modelagem comparativa usando o programa Modeller, que usa um algoritmo de redução das restrições espaciais sobre o alinhamento entre as sequências dos clones e modelos tridimensionais obtidos a partir do Brookhaven Protein Data Bank. Para cada clone, modelou-se três scFv distintos no tamanho dos peptídeos ligantes entre as cadeias leve e pesada: peptídeos ligantes de oito, dez e quinze resíduos foram modelados, gerando, portanto, seis diferentes modelos, os quais foram validados através do servidor MolProbity. Para o docking, utilizou-se o servidor HADDOCK 2.2; e os seis complexos scFv-antígeno gerados foram então submetidos a simulações de Dinâmica Molecular (DM) em campo de força GROMOS 53a6 durante 200 nanossegundos. Ao fim de cada 
simulação, o sistema foi analisado quanto ao desvio e flutuação quadráticos médios, quanto à formação e extinção de pontes salinas e ligações hidrogênio e quanto à variação da área acessível ao solvente de cada complexo.

\section{Resultado:}

Foram modelados três diferentes scFv para cada clone, 19DD1AE3 e 19CC6CG2. Os complexos formados por estes seis fragmentos de anticorpos docados ao seu antígeno, HBsAg, exibiram performances distintas em simulações de dinâmica molecular, com uma diferença dramática na complementaridade estrutural e no número de interações polares intermoleculares.

\section{Conclusão:}

Finalmente, observou-se forte influência do peptídeo ligante sobre a performance de cada modelo nas simulações realizadas. Observou-se ainda que o complexo antígeno-anticorpo é mantido coeso através de ligações hidrogênio intermoleculares, mas não foram encontradas pontes salinas intermoleculares, o que sinaliza para projetos futuros de mutação sítio-dirigida visando aumentar a afinidade dos anticorpos modelados pelo seu antígeno através de interações iônicas dessa natureza.

Palavras-chave: Hepatite B; Modelagem Molecular; Dinâmica Molecular 